\title{
OS DIREITOS FUNDAMENTAIS E A DIGNIDADE DA PESSOA HUMANA NA CONSTITUIÇÃO DA REPÚBLICA FEDERATIVA DO BRASIL DE 1988
}

\section{THE FUNDAMENTAL RIGHTS AND THE DIGNITY OF THE HUMAN PERSON IN THE CONSTITUTION OF THE FEDERATIVE REPUBLIC OF BRAZIL OF 1988}

\author{
Quezia Lucineia de Oliveira da Silva ${ }^{1}$ \\ Helena Nastassya Paschoal Pítsica ${ }^{2}$
}

\begin{abstract}
RESUMO: Existem certos direitos que são inerentes a todos os seres humanos, direitos estes que são considerados substanciais à vida de cada indivíduo. Devido à imprescindibilidade desses direitos, torna-se necessário que haja uma maior garantia de que estesserão observados. Deste modo, ante essa necessidade de maior garantia destes direitos essenciais, passa a ser necessário que sejam positivados na Lei Maior de um país. Quando inseridos na Constituição de determinado país, estes direitos passam a ser tratados como sendo direitos fundamentais. Tal nomenclatura se dá pelo fato de
\end{abstract}

que tais direitos são tão essenciais que precisam obrigatoriamente serobservados com muita cautela. Não são quaisquer direitos que entram para o rol dos fundamentais. Para se enquadrarem nesta categoria é necessário que sejam de extrema relevância, e que visem garantir uma vida digna às pessoas. Logo, pode-se dizer que o maior objetivo em positivar um direito para que esteja dentre os direitos fundamentais é assegurar o princípio da dignidade da pessoa humana. Em se tratando de um princípio, não basta que seja respeitado, é preciso muito mais que isso, é preciso que exista no ordenamento

1 Quezia Lucineia de Oliveira da Silva, pós-graduanda, em nível de especialização em advocacia pública pela Universidade Cândido Mendes, por meio do Portal Educacional F3, aluna do módulo I da Escola Superior da Magistratura Estadual de Santa Catarina (ESMESC), Florianópolis/SC. Email: quezia_oli@hotmail.com.

2 Helena Nastassya Paschoal Pítsica, Doutora, Professora dos Cursos de graduação e pós-graduação da Universidade do Vale do Itajaí e professora de pós-graduação na Escola da Magistratura Estadual de Santa Catarina e da Escola do Ministério Público de Santa Catarina. Email: helena@univali.br. 
jurídico ferramentas que possam de fato assegurá-lo.Assim, é visando a garantia de uma vida com dignidade aos indivíduos que surgem os direitos fundamentais na Lei Maior de um país.

PALAVRAS-CHAVE: Direitos Fundamentais. Dignidade da Pessoa Humana. Constituição.

ABSTRACT: There are certain rights that are inherent to all human beings, rights that are considered essential to the life of each individual. Due to the indispensability of those rights, there is a need for greater assurance that they will be observed, a protection of those rights. Therefore, in view of the need of greater insurance for those essential rights, it becomes necessary that they are affirmed in the Major Law of a country. When inserted in the Constitution of a given country, they become fundamental rights.
Such nomenclature is due to the fact that such rights are so essential that they must be observed with great caution. Not any right can be deemed fundamental. To fit in this category, they must be extremely relevant and aim at ensuring a dignified life to people. Therefore, it can be said that the major objective of affirming a right so it becomes a fundamental right is to ensure the principle of the dignity of the human person. As a principle, it is not enough for it to be respected, it takes much more than that, there must be tools in the legal system that can actually ensure it. Thus, the fundamental rights of the Major Law of a country arise to guarantee a dignified life to its individuals.

KEYWORDS: Fundamental Rights. Dignity of the Human Person. Constitution.

\section{INTRODUÇÃO}

O presente artigo busca discorrer acerca dos direitos fundamentais e sua importância para garantir uma maior segurança jurídica na vida dos indivíduos e com isso assegurar a todos uma vida com dignidade.

Para tanto, inicialmente analisa-se o conceito, a origem e a importância desses direitos bem como o porquê de serem considerados estes fundamentais, de modo que se possa compreender porque existem certos direitos que necessitam de uma maior proteção pelo ordenamento jurídico. Na sequência, trata-se acerca da classificação desses direitos e os momentos históricos em que surgem e a partir de quais reivindicações passam a ser atendidos e respeitados.

Considerando a imposição trazida pela Constituição de 
1988 para concretizar a dignidade da pessoa humana, faz-se necessário que certos direitos essenciais sejam garantidos, pois é através deles que ao menos em partes será possível alcançar uma vida digna.

Consequentemente, ao abordar sobre a necessidade e importância dos direitos fundamentais, verificar-se-á que se tratam de direitos de grande importância para garantir o princípio da dignidade da pessoa humana, e com isso, busca-se atender o que foi imposto pela Constituição. Assim, abordar-se-á sobre o referido princípio e, de uma maneira mais detalhada, sobre sua ligação com estes direitos tidos por fundamentais.

Por fim, será possível verificar que ao elevar um direito como fundamental é ter uma maior segurança de efetividade desse direito ou ao menos uma maior segurança jurídica para reivindicá-lo. Isto porque ainda que tal direito não seja garantido em sua totalidade, se uma pequena parcela que for atendida, ao menos por um momento, será a garantia daquilo que foi prometido em 1988 com a promulgação da Constituição da República Federativa do Brasil.

\section{DIREITOS FUNDAMENTAIS}

Em um primeiro momento, cumpre destacar que todos os seres humanos possuem direitos essenciais à vida, ainda que não sejam legalmente reconhecidos. No entanto, tais direitos não são absolutos, pois à medida em que vão surgindo novas necessidades ao longo do tempo, vão surgindo novos direitos que precisam de uma maior proteção, tanto que surge a necessidade de que sejam tutelados. E assim, com essas novas necessidades e reivindicações por garantia aos novos direitos é que surgem os direitos fundamentais.

Deste modo, para uma melhor compreensão de quais são os direitos considerados fundamentais, destaca-se Jorge Mi- 
randa, que menciona que direitos fundamentais são aqueles direitos ou posições jurídicas estabelecidas na Constituição. (MIRANDA, 2000, p. 7).

Para Robert Alexy, os direitos fundamentais correspondem a uma das cinco marcas dos direitos do homem, e em se tratando do objeto dos direitos do homem (neste caso, os direitos fundamentais), inicia destacando que estes devem tratar de interesses e carências que devem ser protegidos pelo direito, para, em um segundo momento ressaltar que tal carência e interesse deve ser tão fundamental que sua proteção necessite ser fundamentada pelo direito (ALEXY, 2007, p. 45), ou seja, estabelecido na lei maior de um país, a Constituição. Assim, conforme destacou o autor, estes direitos que merecem uma proteção especial devem ser de extrema importância para os indivíduos, isto é, não se trata de qualquer necessidade, é preciso que de fato seja algo fundamental, imprescindível para uma existência digna.

Em se tratando acerca do surgimento dos direitos fundamentais, destaca Dirley da Cunha Júnior que:

[...] como princípios jurídico-constitucionais especiais que
concretizam o respeito à dignidade da pessoa humana, sur-
giram com a criação do Estado Constitucional, no final do
século XVIII, fruto do seu reconhecimento pelas primeiras
normas constitucionais.

Não obstante, é preciso salientar que eles são consequências da própria evolução da humanidade, cujo ideal literário principiara desde a antiguidade, a partir da concepção de direitos inatos do homem, em razão de sua, unicamente, condição humana. (DIRLEY JR, 2012, p. 585).

Assim, considerando que os direitos fundamentais tratamse de direitos que surgem a partir dos interesses dos indivíduos e à medida em que a sociedade vai evoluindo, tem-se que tais direitos passam a existir ao passo em que novos acontecimentos vão surgindo e, com isso, passam a confrontar certos 
valores considerados fundamentais. Logo, vai tornando-se necessária a existência de regulamentações sobre esses valores atingidos, ou seja, torna-se necessário o nascimento de novos direitos que regulem determinados assuntos até então não assegurados. (VERONESE; OLIVEIRA, 2013, p. 55).

Sendo que se tratam de direitos que vão surgindo a partir de novas necessidades, verifica-se que não se tratam de direitos absolutos, pois conforme leciona Norberto Bobbio:

[...] os direitos do homem constituem uma classe variável, como a história destes últimosséculos demonstra suficientemente. $\mathbf{O}$ elenco dos direitos do homem se modificou, e continua a se modificar,com a mudança das condições históricas, ou seja, dos carecimentos e dos interesses, das classes no poder, dosmeios disponíveis para a realização dos mesmos, das transformações técnicas, etc. Direitos que foram declarados absolutos no final do século XVIII, como a propriedade sacre et inviolable, foram submetidos a radicaislimitações nas declarações contemporâneas; direitos que as declarações do século XVIII nem sequer mencionavam,como os direitos sociais, são agora proclamados com grande ostentação nas recentes declarações. Não é difícil prever que, no futuro, poderão emergir novas pretensões que no momento nem sequer podemos imaginar, como o direito a não portar armas contra a própria vontade, ou o direito de respeitar a vida também dos animais e não só dos homens. $\mathrm{O}$ que prova que não existem direitos fundamentais por natureza. $\mathbf{O}$ que parece fundamental numa época histórica e numa determinada civilização não é fundamental em outras épocas e em outras culturas. (BOBBIO, 2004, p. 13, grifo nosso).

Neste Contexto, destaca-se que "[...] cada passo na etapa da evolução da humanidade importa na conquista de novos direitos." (SILVA, 2014, p. 05). E, com isso, depreende-se que é a partir da constante transformação e consequentemente das novas reivindicações dos indivíduos, que vão surgindo novos direitos a serem positivados, de modo que possam atender as 
recentes necessidades da sociedade.

Assim sendo, para alcançar a atual etapa de reconhecimento e proteção desses direitos tidos por fundamentais, destaca-se que isto se deu de maneira lenta e gradual, à medida em que foram sendo alcançadas determinadas fases, e a essas fases foram denominadas gerações, devido terem sido esses direitos reivindicados em diferentes momentos da história. (PICADO, 2010, p. 54). Deste modo, para que sejam melhores atendidas as novas necessidades originadas devido ao processo de evolução é que "[...] de cada processo de evolução serão positivadas uma geração de direitos." (GARCIA; MELO, 2009, p. 303).

Neste sentido, traz Norberto Bobbio, que esta evolução torna-se necessária, pois os direitos são cada vez mais extensos, e "[...] à medida que as pretensões aumentam, a satisfação delas torna-se cada vez mais difícil”, portanto, há sempre a necessidade da positivação de novos direitos. (BOBBIO, 2004, p.60).

Para fins de identificação dos direitos fundamentais, em que pese haver diferentes classificações por parte dos doutrinadores, considerar-se-á aquela que traz como sendo três as gerações dos direitos fundamentais, quais sejam: os direitos de primeira geração que trazem o reconhecimento das liberdades, seriam então os direitos fundamentais do homem como indivíduo, ou seja, são os direitos individuais que dão certa autonomia ao indivíduo; quanto os direitos fundamentais de segunda geração, estes consagram os direitos sociais, que seriam os direitos do homem como membro de uma coletividade; e os de terceira geração, que são os direitos de solidariedade ou fraternidade, referem-se aos direitos do homem solidário, pois de um modo geral, este se preocupa também com a humanidade, e não apenas com si mesmo. (MENDES; BRANCO, 2014, p. 137-138).

Os direitos de primeira geração, surgiram visando a proteção do indivíduo diante do Estado. É a partir da identificação 
desses direitos que passa a existir o "não agir", e até mesmo um certo afastamento do Estado, isto é, o Estado sai de sua forma absoluta de modo a garantir mais liberdade e autonomia ao indivíduo. Ponto marcante para este novo paradigma do Estado, ocorreu na Revolução Francesa, com a Declaração Universal dos Direitos do Homem e do Cidadão, em 1789 e também na Revolução Americana com a Declaração de Direitos da Virgínia em 1776. (MARMELSTEIN, 2009, p. 42- 44).

Considerando que este afastamento do Estado não resultou em algo apenas positivo, uma vez que não era possível garantir as necessidades básicas da sociedade, passou a surgir a necessidade de um reformismo, de uma revolução que superasse as desigualdades.

Deste modo, ante essa necessidade de uma maior atenção do Estado para com os anseios da sociedade, advém o Estado Social, que por sua vez, está atrelado à igualdade entre os indivíduos. Esta é garantida através de uma prestação positiva do Estado, pois aqui Ele atua em favor do cidadão para que seja garantida a igualdade entre todos, atendendo as reivindicações de justiça social, e às relações sociais e culturais do indivíduo. (FERREIRA FILHO, 2009, p. 86-87). Tais direitos passaram a ser reivindicados a partir da Revolução Industrial em meados do século XIX, no entanto, passaram a ser melhores observados "[...] a partir do início do século XX, passando a figurar nas Constituições, de modo mais marcante, desde a Segunda Guerra Mundial." (CHIMENTI, et al., 2008, p. 47).

Com a passar do tempo explicitou-se que não bastava existir apenas a liberdade e igualdade, pois não é suficiente que cada um aja por si só, é necessário mais que isso, é preciso que todos pensem no seu próximo e no meio em que vivem, é preciso que haja solidariedade entre os indivíduos. Assim, devido a esta necessidade de solidariedade entre os indivíduos é que surgiram os direitos fundamentais de terceira geração."Direitos estes que 
desprendem-se da figura do indivíduo, destinando-se à proteção de grupos humanos." (SBROGIO'GALIA, 2007, p. 127).

Observando a evolução os direitos fundamentais, percebese que foram ocorrendo ao longo do tempo, visto que a cada momento em que foram surgindo novas temáticas, devido às constantes transformações que ocorreram no mundo, foi sendo preciso enquadrar tais situações no ordenamento jurídico. Isso ocorreu pelo fato de que estas situações inovadoras passaram a tornar-se tão fundamentais na vida do homem que necessitaram de amparo legal para resguardá-las, assim, sendo possível assegurar aquilo que condiz com os interesses do homem.

Contudo, é importante frisar que, muito embora existam essas classificações das gerações dos direitos fundamentais, isso não quer dizer que cada geração trata de apenas alguns direitos específicos, ou que haja exclusividade de certos direitos em cada geração, muito pelo contrário, pois "[...] essa distinção entre gerações dos direitos fundamentais é estabelecida apenas com o propósito de situar os diferentes momentos em que esses grupos de direitos surgem como reivindicações acolhidas pela ordem jurídica..” (MENDES; BRANCO, 2014, p. 138).

À vista disso, pode-se dizer que a distinção e separação entre as gerações de direitos se dá apenas para guardar uma ordem histórica e cronológica, e não para limitar os grupos de direitos que podem ser positivados em cada geração. Pois apenas estando em constante transformação é que os direitos fundamentais estarão cada vez mais próximo de atender as novas demandas, e com isso cada vez mais será possível assegurar uma vida com mais dignidade aos indivíduos.

\section{DIREITOS FUNDAMENTAIS COMO GARANTIA DA DIGNIDADE DA PESSOA HUMANA}

A dignidade da pessoa humana é o que une os direitos 
fundamentais essenciais aos indivíduos, ela é uma referência constitucional dos direitos que propõem-se a garantir o conforto e a proteção das pessoas, com isso, protegendo-as daqueles sofrimentos possíveis de serem evitados. (CHIMENTI et al., 2008, p. 34).

Assim sendo, tais direitos tornam-se então fundamentais de modo a assegurar uma vida com mais dignidade para o indivíduo, pois conforme aduz Konrad Hesse “[...] os direitos fundamentais devem criar e manter as condições elementares para assegurar uma vida em liberdade e a dignidade humana." (HESSE, 2009, p. 33).

Neste sentido é que George Marmelstein destaca que:

Os direitos fundamentais são normas jurídicas, intimamente ligadas à ideia de dignidade da pessoa humana e de limitação do poder, positivadas no plano constitucional de determinado Estado Democrático de Direito [...]. Se determinada norma jurídica tiver ligação com o princípio da dignidade da pessoa humana ou com a limitação do poder e for reconhecida pela constituição de um Estado Democrático de Direito como merecedora de uma proteção especial, é bastante provável que se esteja diante de um direito fundamental. (MARMELSTEIN, 2009, p. 20, grifo nosso).

Destarte, sabendo a ligação dos direitos fundamentais com a dignidade da pessoa humana, busca-se então definição do que seria essa dignidade da pessoa humana, embora Ingo Wolfgang Sarlet (2006, p. 39) destaque não ser algo tão fácil de se obter um conceito, pelo menos não de forma muito clara, mas pontua que "[...] a dignidade da pessoa humana na condição de valor (e princípio normativo) fundamental [...] exige e pressupõe o reconhecimento e proteção dos direitos fundamentais de todas as dimensões", logo, negar ao indivíduo os direitos fundamentais que lhe pertencem, seria o mesmo que negar a própria dignidade desse indivíduo. 
Neste mesmo sentido é que em relação à dignidade da pessoa humana Luiz Fernando Barzotto aduz que se exige que o ser humano venha ser reconhecido como pessoa, de modo que ao dizer "[...] que uma conduta ou situação viola a dignidade da pessoa humana significa que nesta conduta ou situação o ser humano não foi reconhecido como pessoa." (BARZOTTO, 2010, p. 51).

No entanto, na busca por uma melhor compreensão, Ingo Wolfgang Sarlet inspirado em Günter Dürig, coloca que por ser uma qualidade inerente à pessoa humana, a dignidade tratase de algo irrenunciável e inalienável, e deste modo constitui "[...] elemento que qualifica o ser humano como tal e dele não pode ser destacado, de forma que não se pode cogitar a possibilidade de determinada pessoa ser titular de uma pretensão a que lhe seja concedida a dignidade." (SARLET, 2006, p. 41).

Sendo uma qualidade inerente ao ser humano, entende Lara Vanessa Millon, que, para que seja respeitada a dignidade da pessoa humana é preciso que seja garantida a liberdade, de modo que as pessoas sejam livres para desenvolver suas personalidades. Além da liberdade, é necessário ainda que o ser humano jamais venha ser tratado de modo degradante, humilhante ou de modo que seja ofensivo a sua dignidade. Logo, em se tratando do que guarda relação com o indivíduo, e "[...] que tenha relação estreita com sua vontade e autonomia na vida em sociedade, tudo o quanto lhe possibilite autodeterminação está assegurado pelo princípio da dignidade humana." (MILLOM, 2007, p. 24).

É nessa linha de pensamento, que inspirado em Michael Sachs, Ingo Wolfgang Sarlet refere-se à dignidade da pessoa humana, ao expor o seguinte:

Onde não houver respeito pela vida e pela integridade física e moral do ser humano, onde as condições mínimas para uma existência digna não forem asseguradas, onde não houver limitação do poder, enfim, onde a li- 
berdade e a autonomia, a igualdade (em direitos e dignidade) e os direitos fundamentais não forem reconhecidos e minimamente assegurados, não haverá espaço para a dignidade da pessoa humana e esta (a pessoa), por sua vez, poderá não passar de mero objeto de arbítrio e injustiças. Tudo, portanto, converge no sentido de que também para a ordem jurídico-constitucional a concepção do homem-objeto (ou homem-instrumento), com todas as consequências que daí podem e devem ser extraídas, constitui justamente a antítese da noção de dignidade da pessoa [...]. (SARLET, 2006, p. 59, grifo nosso).

Deste modo, em se tratando dos direitos fundamentais, bem como da dignidade da pessoa humana na Constituição da República Federativa do Brasil de 1988, não se quer dizer que anteriormente não existiam, muito pelo contrário, tais direitos apenas não estavam sendo observados no ordenamento jurídico com o devido cuidado.

Ainda ressalta George Marmelstein, em relação aos direitos fundamentais, que "[...] sempre houve uma consciência de que existiam valores ligados à dignidade", isto é, existiam sim valores que visavam garantir, assegurar uma vida digna às pessoas. Entretanto, destaca o autor que pelo fato de que tais valores não eram ainda positivados no ordenamento jurídico, não havia a possiblidade de o cidadão solicitar que determinado valor lhe fosse assegurado, não havia meios para exigir algo que fosse contribuir para sua vida digna se este não estivesse expressamente garantido em alguma Lei. Desse modo, se não havia um reconhecimento formal apontando que aquele valor específico era um direito assegurado, têm-se que não era possível reivindicar um direito que em regra não existia, ou seja, até existia, mas não era positivado, não havia um fundamento legal para esta reivindicação. (MARMELSTEIN, 2009 p. 33).

Compreendendo o pensamento retro, o Estado é reativo, ele atende aos anseios da sociedade, e dessa forma para uma maior 
garantia dos direitos fundamentais é que com a Constituição de 1988 tais direitos passaram a estar presentes no ordenamento jurídico brasileiro. Passa então a dignidade da pessoa humana a ser considerada como um princípio fundamental, estando presente no artigo $1^{\circ}$ da Constituição da República Federativo do Brasil, que dispõe o seguinte:

Art. $1^{\circ}$ A República Federativa do Brasil, formada pela União indissolúvel dos Estados e Municípios e do Distrito Federal, constitui-se em Estado Democrático de Direito e tem como fundamentos:

$[\ldots]$

III- a dignidade da pessoa humana. (BRASIL, 1988).

Assim, verifica-se a importância do princípio da dignidade da pessoa humana, de modo que "[...] nos dias de hoje, já não é mais aceitável pensarmos em Estado Democrático de Direito que não assegure ou reconheça a dignidade da pessoa humana como princípio basilar.” (MILLON, 2007, p. 20).

Além de trazer a dignidade da pessoa humana como princípio fundamental e consagrar inúmeros direitos fundamentais, a Constituição de 1988 também se propôs a reconhecer e adotar tratados em que o Brasil faz parte, conforme preconiza o art. $5^{\circ} \S \S 2^{\circ}$ e $3^{\circ}$ :

$\S 2^{\circ}$ Os direitos e garantias expressos nesta Constituição não excluem outros decorrentes do regime e dos princípios por ela adotados, ou dos tratados internacionais em que a República Federativa do Brasil seja parte.

$\S 3^{\circ}$ Os tratados e convenções internacionais sobre direitos humanos que forem aprovados, em cada Casa do Congresso Nacional, em dois turnos, por três quintos dos votos dos respectivos membros, serão equivalentes às emendas constitucionais. (BRASIL, 1988).

Com isso, evidencia-se que no tocante às mudanças em re- 
lação aos direitos fundamentais trazidas pela Constituição de 1988, não param por aí, pois diferente de todas as Constituições anteriores, desta vez o Constituinte optou por privilegiar os direitos fundamentais, trazendo-os para o início da Constituição, logo no segundo título, com o tema "Dos direitos e garantias fundamentais." (BRASIL, 1988). Salienta também George Marmelstein (2009 p. 69) que com isso o Constituinte optou por favorecer os direitos fundamentais com a verdadeira intenção de que tais direitos sejam de fato respeitados, atendidos, que sejam concretizados e não simplesmente proclamados.

Corroborando com este posicionamento, Nadia Rejane Chagas Marques (2012, p. 29), ao falar sobre os direitos da pessoa humana, leciona que tais direitos representam um extraordinário avanço da modernidade, pois é a partir desses direitos (da pessoa humana) que as pessoas "[...] não podem abrir mão de uma esfera de proteção que lhes assegure valores ou interesses fundamentais". E ainda ressalta a referida autora, que "interpretar a "Lei Maior", segundo a principiologia que a rege, implica conferir-lhe eficácia". Deste modo, o indivíduo tem a possibilidade de reivindicar seus direitos, pois desta vez eles encontram-se positivados, e assegurados pela constituição.

Ainda nesta linha de pensamento e em consonância ao que traz o dispositivo Constitucional retromencionado, Alexandre de Moraes destaca que sendo um princípio fundamental, a dignidade da pessoa humana:

Concede unidade aos direitos e garantias fundamentais, sendo inerentes às personalidades humanas. Esse fundamento afasta a ideia de predomínio das concepções transpessoalistas de Estado e Nação, em detrimento da liberdade individual. A dignidade é um valor espiritual e moral, inerente à pessoa, que se manifesta singularmente na autodeterminação consciente e responsável da própria vida e que traz consigo a pretensão ao respeito por parte das demais pessoas, constituindo-se um mínimo invulnerável que todo 
estatuto jurídico deve assegurar, de modo que, somente excepcionalmente, possam ser feitas limitações ao exercício dos direitos fundamentais, mas sempre sem menosprezar anecessária estima que merecem todas as pessoas enquanto seres humanos. (MORAES, 2007, p. 16, grifo do autor).

A partir da positivação dos direitos e garantias fundamentais, bem ainda com o enfoque e valoração dada à dignidade da pessoa humana, verifica-se que estes vieram como resposta aos anseios da sociedade, pois como George Marmelstein (2009, p. 66) bem alude, "[...] nossa Constituição pretendeu sepultar o cadáver autoritário da ditadura militar e representou, para os brasileiros, a certidão de nascimento de uma democracia tardia, mas sempre aguardada".

Destarte, consoante ao que traz Paulo Ricardo Schier (2014, p. 46), é compreensível "[...] o significado e força simbólicos que foram atribuídos à Constituição de 1988", uma vez que veio em um momento tão propício, em que a sociedade realmente clamava por inúmeras mudanças em vários sentidos. E como complemento deste posicionamento, concernente à Constituição de 1988, Luís Roberto Barroso (2000, p. 42) ensina que esta "[...] tem a virtude de espelhar a reconquista dos direitos fundamentais, [...] simbolizando a superação de um projeto autoritário, pretensioso e intolerante que se impusera ao País".

Neste sentido, Paulo Ricardo Schier, sublinha que a Constituição de 1988, devido a tudo o que consagrou, passou a ser conhecida como sendo uma "Constituição Cidadã", porquanto:

Conhecida como "Constituição Cidadã", a lei fundamental em vigor consagrou a democracia, retomou o Estado de Direito, afirmou uma série de princípios fundamentais pautados na tutela da dignidade da pessoa humana [...]. Consagrou ainda, extenso rol de direitos fundamentais. Inovou, neste campo, ao incluir um significativo número de direitos sociais vinculados à ordem econômica, ao trabalho, à cultura etc. Ao mesmo tempo em que garantiu direitos que já 
haviam sido incorporados ao patrimônio histórico e jurídico da comunidade brasileira, também apresentou algumas respostas para problemas do passado [...] e projetos para o futuro. (SCHIER, 2014, p. 45).

Nesta circunstância, visando melhor esclarecer o porquê de ser conhecida como "Constituição Cidadã", conforme mencionou o autor supracitado, faz-se necessário realçar o destaque feito por George Marmelstein, ao trazer que ao ser promulgada a Constituição, em 5 de outubro de 1988, Ulisses Guimarães proferiu um discurso enaltecendo-a, quando declarou que:

O Homem é o problema da sociedade brasileira: sem salário, analfabeto, sem saúde, sem casa, portanto sem cidadania. A Constituição luta contra os bolsões de miséria que envergonham o país. Diferentemente das sete constituições anteriores, começa com o homem. Graficamente testemunha a primazia do homem, que foi escrita para o homem, que o homem é seu fim e sua esperança. É a Constituição cidadã. (MARMELSTEIN, 2009 p. 66, grifo nosso).

Referindo-se a este discurso, George Marmelstein (2009, p. 66) acentua que fica evidente o que a Constituição de 1988 passa a representar, pois ainda que exista a possibilidade de não ser efetivada, ela apresenta uma postura de coragem "[...] em favor da redução das desigualdades sociais, dos oprimidos, dos direitos fundamentais, da democracia e de todos os valores ligados à dignidade da pessoa humana”.

A partir de todas as inovações e melhorias trazidas pela Constituição de 1988, cumpre ressaltar que de um modo geral "[...] trata-se de texto que, em seu conjunto, afirma o Estado Social." (SCHIER, 2014, p. 45). Isto porque, segundo já demonstrado, esta foi uma Constituição que deu grande enfoque nos diretos fundamentais, direitos sociais e passou a dar maior valor à dignidade da pessoa humana, tanto que a consagrou como princípio fundamental. 
Com toda essa valoração dada aos direitos fundamentais e o princípio da dignidade da pessoa humana, observa-se que realmente trata-se de uma Constituição que se preocupa em garantir uma vida digna. Deste modo, com inspiração em Volker Neumann, é que Ingo Wolfgang Sarlet e Mariana Flichtiner Figueiredo (2010, pp. 21-22) ressaltam que a real garantia para uma vida digna "[...] abrange mais do que a garantia da mera sobrevivência física, [...] uma vida sem alternativas não corresponde às exigências da dignidade humana, a vida humana não pode ser reduzida à mera existência".

Realmente a Constituição vem com tamanho intuito em garantir direitos fundamentais, dignidade da pessoa humana, dentre outros, que desde o preâmbulo já assegura determinados direitos. $\mathrm{E}$ em que pese não ter natureza jurídica, o preâmbulo tem uma certa força simbólica, de modo que serve de auxílio na interpretação de outras normas, de acordo com George Marmelstein (2009, p. 67). Assim, importante ressaltar o preâmbulo da Constituição:

Nós, representantes do povo brasileiro, reunidos em Assembléia Nacional Constituinte para instituir um Estado Democrático, destinado a assegurar o exercício dos direitos sociais e individuais, a liberdade, a segurança, o bem-estar, o desenvolvimento, a igualdade e a justiça como valores supremos de uma sociedade fraterna, pluralista e sem preconceitos, fundada na harmonia social e comprometida, na ordem interna e internacional, com a solução pacífica das controvérsias, promulgamos, sob a proteção de Deus, a seguinte CONSTITUIÇÃO DA REPÚBLICA FEDERATIVA DO BRASIL. (BRASIL, 1988).

Deste modo, realmente resta claro que a medida em que as pessoas buscam e começam a reivindicar por mudanças, o Estado tende a responder tais reivindicações, visando sempre atender os anseios do povo de um modo que verifique ser o melhor para todos. Assim, observa-se que passou a existir uma 
maior necessidade de garantir uma vida digna às pessoas, e com a Constituição de 1988, o Estado busca então responder tais anseios garantindo uma vida digna ao povo brasileiro, pois com isso passa a existir uma maior garantia de poder usufruir de todos os direitos fundamentais que a Constituição proporciona à sociedade brasileira.

\section{CONCLUSÃO}

Baseando-se na pesquisa realizada, percebe-se que para que o indivíduo possa viver dignamente é preciso que lhe sejam assegurados determinados direitos, e para que isto ocorra, de uma forma mais garantida, é necessário que estes direitosestejam positivados na Constituição de um país, para então serem considerados direitos extremamente essenciais à vida, ou seja, "direitos fundamentais", direitos sem os quais corre-se o risco de não se ter uma vida digna de acordo com o que preconiza a Constituição da República Federativa do Brasil de 1988.

Assim, tratando-se de direitos fundamentais, e uma vez que como tais visam assegurar o princípio da dignidade da pessoa humana, verifica-se a tamanha necessidade da proteção desses direitos, de modo que precisam, de fato, serem efetivados. Em caso da não efetivação desses direitos, pode-se dizer que de certa forma estaria sendo colocada em risco a existência digna do indivíduo, uma vez que o mecanismo mais forte para garantir a dignidade da pessoa humana, trazida como fundamento pela Constituição de 1988, são os direitos fundamentais.

Estes direitos foram surgindo ao passo em que foram surgindo novos anseios da sociedade, anseios para tutelar as novas situações que passaram e passam a existir com a constante transformação do mundo. Portanto, de acordo com a necessi- 
dade de cada momento histórico passou-se a perceber que para se ter uma vida digna seria preciso que mais direitos fossem garantidos, isto porque com a positivação de novos direitos há maior segurança para os indivíduos.

Devido à relevância dos direitos fundamentais, principalmente em se tratando de assegurar a dignidade humana, constata-se que quando não for possível assegurá-los num todo, é preciso que ao menos em partes os direitos fundamentais sejam garantidos, pois ao serem considerados fundamentais, esses direitos são considerados extremamente essenciais, portanto, não devem ser simplesmente respeitados, muito mais do que isso, eles devem ser garantidos, assegurados e efetivados.

Somente sendo verdadeiramente assegurados e garantidos os direitos fundamentais é que os indivíduos poderão de fato gozar uma vida digna que está dentro daquilo que não afronta o princípio da dignidade da pessoa humana, uma vida digna de acordo com o princípio fundamental estabelecido pela nossa Constituição.

\section{REFERÊNCIAS}

ALEXY, Robert. Constitucionalismo discursivo. Tradução Luís Afonso Heck. Porto Alegre: Livraria do Advogado, 2007.

BARROSO, Luís Roberto. O direito constitucional e a efetividade de suas normas: limites e possibilidades da constituição brasileira. 4. ed. ampl. e atual. Rio de Janeiro: Renovar, 2000.

BARZOTTO, Luiz Fernando. Pessoa e reconhecimento - uma análise estrutural da dignidade da pessoa humana. In: ALMEIDA FILHO, Agassiz; MELGARÉ, Plínio. (Org.). Dignidade da Pessoa Humana: fundamentos e critérios interpretativos. São Paulo: Malheiros, 2010.

BOBBIO, Norberto. A era dos direitos. Tradução Carlos Nelson Coutinho. 7. ed. Rio de Janeiro: Elsevier, 2004.

BRASIL, Constituição da República Federativa do Brasil de 1988. Disponível em: $<$ http://www.planalto.gov.br/ccivil_03/constituicao/ConstituicaoCompilado.htm>. Acesso em: 12 nov. 2017. 
CHIMENTI, Ricardo. Cunha; SANTOS, Marisa Ferreira dos; ROSA, Marcio Fernando Elias;

CAPEZ, Fernando. Curso de direito constitucional. 5. ed. rev. e atual. São Paulo: Saraiva, 2008.

CUNHA JR, Dirley da. Curso de direito constitucional. 6. ed. rev. ampl. e atual. Bahia: Juspodivm, 2012.

FERREIRA FILHO, Manoel Gonçalves. Princípios fundamentais do direito constitucional. São Paulo: Saraiva, 2009.

GARCIA, Marcos Leite; MELO, Osvaldo Ferreira de. Reflexões sobre o conceito de direitos fundamentais. Revista Eletrônica Direito e Política, Programa de Pós-Graduação Strictu Sensu em Ciência Jurídica da UNIVALI, Itajaí, v.4, n.2, $2^{\circ}$ quadrimestre de 2009. p. 303. Disponível em: < http://siaiap32.univali.br/seer/index.php/rdp/article/ viewFile/7231/4118>. Acesso em: 20 set. 2017.

HESSE, Konrad. Temas fundamentais do direito constitucional. Tradução Carlos dos Santos Almeida. São Paulo: Saraiva, 2009.

MARQUES, Nadia Rejane Chagas. O direito à saúde no Brasil: entre a norma e o fato. Porto Alegre: Núria Fabris, 2012.

MARMELSTEIN, George. Curso de direitos fundamentais. 2. ed. São Paulo: Atlas, 2009.

MENDES, Gilmar Ferreira; BRANCO, Paulo Gustavo Gonet. Curso de direito constitucional. 9. ed. São Paulo: Saraiva, 2014. p. 137- 138.

MILLON, Lara Vanessa. Princípio da dignidade da pessoa humana e acesso à justiça. Ano 2007. 146 f. Dissertação - Universidade Presbiteriana Mackenzie. São Paulo, 2007. Disponível em: <http://www.dominiopublico.gov.br/download/teste/arqs/ cp061787.pdf $>$ Acesso em: 30 set. 2017.

MIRANDA, Jorge. Manual de direito constitucional: direitos fundamentais. 3. ed. rev. e atual. Coimbra: Coimbra, 2000.

NEUMANN, Volker. apud SARLET, Ingo Wolfgang. FIGUEIREDO, Mariana Filchtiner. Reserva do possível, mínimo existencial e direito à saúde: algumas aproximações. In: Direitos fundamentais: orçamento e "reserva do possível". (Org.). Ingo Wolfgang Sarlet, Luciano Benetti Timm (et. al). 2. ed. rev. e ampl. Porto Alegre: Livraria do Advogado, 2010.

PICADO, Fernanda de Siqueira. A dignidade da pessoa humana e a efetividade do direito social à saúde sob a óptica jurisprudencial. Ano 2010. 147 f. Dissertação - Pontifícia Universidade Católica de São Paulo. São Paulo, 2010. Disponível em: <http:// bdtd.ibict.br/vufind/Record/PUC_SP1_06156421d9f2c3bf3283628dfdf2081e\#details. Acesso em: 12 abr. 2016.

SARLET, Ingo Wolfgang. Dignidade da pessoa humana e direitos fundamentais: na Constituição Federal de 1988. 4. ed. rev. e atual. Porto Alegre: Livraria do Advogado, 2006.

SBROGIO'GALIA, Susana. Mutações constitucionais e direitos fundamentais. Porto Alegre: Livraria do Advogado, 2007. 
SCHIER, Paulo Ricardo. Constitucionalização do direito no contexto da Constituição de 1988. In: CLÉVE, Clémerson Merlin (Org.). Direito constitucional brasileiro: teoria da constituição e direitos fundamentais. São Paulo: Revista dos Tribunais, 2014.

SILVA, Afonso José da. Curso de direito constitucional positivo. 37. ed. rev. e atual. São Paulo: Malheiros, 2014.

VERONESE, Josiane Rose Petry; OLIVEIRA, Olga Maria B. Aguiar. Direito e fraternidade. Rio de Janeiro; Lumen Juris, 2013.

Recebido em: 30/05/2018

Aprovado em: 20/08/2018 